\title{
Tenochtitlan - An Interactive Virtual Reality Environment That Encourages Museum Exhibit Engagement
}

\author{
Sebastian Garcia-Cardona, Dr Feng Tian, Dr Simant Prakoonwit \\ ${ }^{1}$ Faculty of Science \& Technology, Bournemouth University, Bournemouth, BH12 5BB, UK \\ ${ }^{2}$ Springer Heidelberg, Tiergartenstr. 17, 69121 Heidelberg, Germany \\ Incsespringer.com
}

\begin{abstract}
With many cultural institutions experiencing declining visitor figures, a large number have begun introducing the use of engaging technologies to attract more visitors, the use of which seem especially appealing to the younger generations. Due to the steadily rising popularity of virtual reality, it is one of the more prominent technologies these institutions have incorporated. However, most uses of virtual reality result in small-scale exhibit recreations or immersive video with very little interaction. In this paper, we propose to create a large-scale virtual reality environment with an integrated interactive quiz system, which aims to offer an engagement level above that of traditional museum exhibits. Initial results of Tenochtitlan have been demonstrated positive. Participant interviews have shown that $87.5 \%$ experienced engagement levels in Tenochtitlan greater than that of a traditional museum exhibit, and $62.5 \%$ stated that their knowledge of the subject matter had increased.
\end{abstract}

Keywords: Museum Virtual Reality, Museum Exhibit Engagement, Interactive Learning

\section{Introduction}

In recent years, many cultural institutions have seen their visitor figures stagnate or decline [1]. The heavy use of digital technology could be partly to blame, as it makes up a large percentage of how we choose to spend our leisure time [2], with younger generations even less likely to visit museums, galleries etc. One recent technology, in particular, seems to have captured the interest of these same young people: virtual reality [3].

Virtual reality technology has advanced massively in the last decade [4], to the point where consumer-level VR devices have become freely available to the public. Subsequently, virtual reality technology has seen a rise in popularity. Cultural institutions have tried to capitalise on this popularity by using virtual reality with their exhibits to attract visitors [5] in a time where figures have been falling.

Many current forms of virtual reality integration by museums currently exist, most of which result in a highly immersive experience. In 2015 the British Museum held the 'Virtual Reality Weekend' [6], an event where users could use a Samsung Gear VR to 
explore a Bronze Age roundhouse and view 3D-scanned exhibit artefacts. It proved extremely popular, attracting over 1,200 visitors during the two-day event. The National History Museum in London has employed VR technology in several ways [7] [8], the first example being a 360-degree VR video titled 'David Attenborough's Great Barrier Reef Dive'. They have also recently made many of their exhibits available to view remotely in VR using Google Cardboard, along with the option to see an ancient reptile swim around the user while they learn facts about it.

The methods in which the National History Museum have made use of virtual reality seem to be the most widespread amongst museums i.e. exhibit recreation in VR and 360 VR videos. However, these examples, as with many others, seem to overlook the capacity for interaction provided by the technology [9].

In this paper, we propose and develop an educational virtual reality environment, called Tenochtitlan. Tenochtitlan is intended to be used as a complementary tool to increase engagement levels with existing museum exhibits. The environment is explored in first person and integrates an interactive quiz system, designed to maximise information delivery and retention over that provided by traditional museum methods.

Participants who were asked to take part in Tenochtitlan's virtual reality quiz, and were subsequently interviewed, have produced positive initial results which will be discussed further in section 4 .

\section{Suitability of Virtual Reality}

Many museums already make use of multimedia technologies to complement existing exhibits as a means of making them more dynamic and engaging [10]. Virtual reality technology expands on this with the ability to wholly immerse the viewer in a realistic environment and gives them the opportunity to view artefacts in greater detail, resulting in a more engrossing experience.

In recent years, the benefits of virtual reality (and gamification) use in educational environments have been researched extensively, with many studies noting the positive outcomes in both education delivery and engagement levels [5] [6] [11].

Despite its benefits, virtual reality does have certain limitations not found in the traditional methods of information delivery currently found in museums [5]. Firstly, the employment of VR technology has been proved costly to museums [12]; and secondly, the creation of a VR application requires much more resources, in both time and people, than text-and-image based information delivery [13].

There also exists the need for a careful balance when creating virtual reality applications which include educational elements as one of their intended outcomes. The application must be designed in a way that avoids the appeal of the technology itself overshadowing the element intended to be presented to the user.

However, when executed well the resulting applications can prove highly effective. This has been shown in a study conducted by [14] testing the exhibit engagement levels in a children's science museum. These positive findings were echoed in a separate study by [15], which found that $70 \%$ of visitors agreed that the use of virtual reality "...enhanced the visitor experience". 
Furthermore, a preliminary survey conducted across 50 individuals found a positive attitude towards virtual reality in museums, the results of which can be seen in Fig. 1 and Fig. 2.

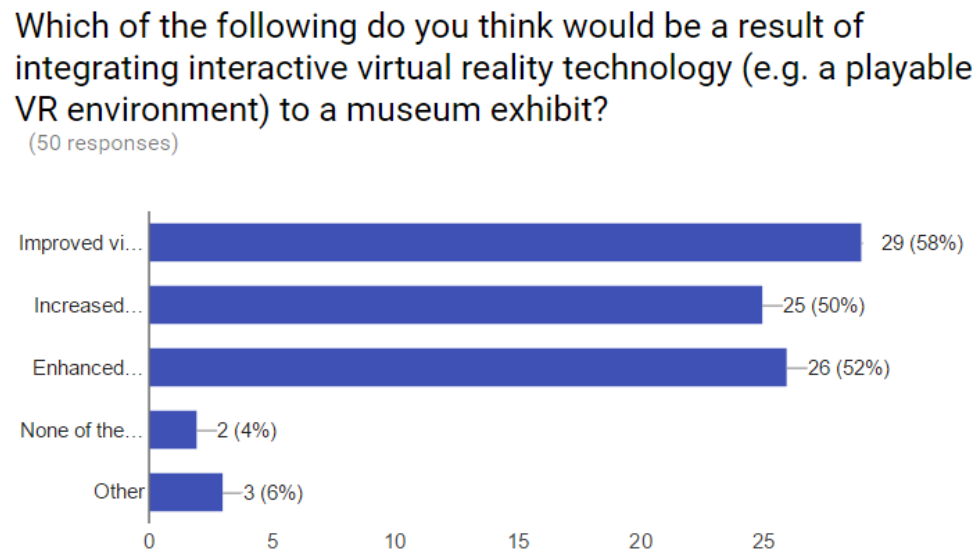

Fig. 1. 52\% of respondents believe the inclusion of interactive VR would enhance visitor-exhibit engagement.

Would the use of interactive virtual reality technology in a museum make you more likely to visit?

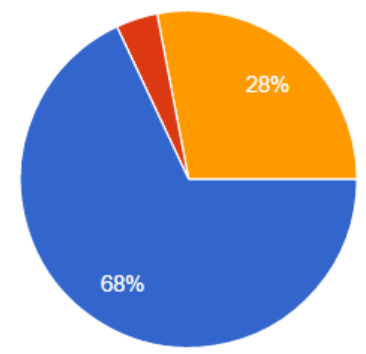

Yes, I'd be more likely to visit

No, l'd be less likely to visit

It would not affect my

likelihood of visiting a museum

Fig. 2. 68\% of those surveyed commented that the inclusion of a VR-integrated exhibit would increase their likelihood of visiting a museum.

\section{Application Design}

Our application Tenochtitlan has been tailored towards young adults aged 18-30, as this is the age group that museums seem to be struggling to attract the most [16]. As this element of the design mainly entailed regulating the language used and the questions within the quiz, Tenochtitlan could be modified to suit other target age groups relatively 
easily. Another consideration made during the design stage was that of the user's technological competence, which was assumed to be basic for the sake of this project. This allowed Tenochtitlan to remain accessible to as wide an audience as possible, without alienating individuals who lack experience with game technology.

\subsection{The Application}

Tenochtitlan is an interactive virtual reality environment which offers users the opportunity to explore a portion of an ancient Aztec city. Its purpose is to increase the user's engagement with, and knowledge of, the subject matter through the use of virtual reality technology. To achieve this Tenochtitlan incorporates two core design dynamics: exploration and educational delivery by means of a quiz system.

When the user starts up Tenochtitlan, they are greeted with a notice board with instructions on what their objectives are, and how they will interact with the environment. These introduction/instructions were kept short and make use of simple language to ensure that possible user confusion is kept to a minimum.

As the user explores the environment they will encounter several pop-ups along the way. Half of these are informational and display facts about the Aztecs to the user. This assists in the educational aspect of Tenochtitlan, which in an exhibit would normally be achieved through regular image/text information delivery methods [9].

The other half of these pop-ups contain questions, which form Tenochtitlan's main mechanic: the quiz system. The questions in these are tied directly to corresponding factual pop-ups. To answer these questions the player aims at their selection using the VR reticule and presses a button on the controller. Separate pop-ups, along with audio cues, inform the player if they have answered correctly or not. If they have answered correctly, then their level score will be updated to reflect this. The inclusion of a score mechanic as a positive feedback loop is one that aims to provide an incentive for the users to further explore the environment [17].

The quiz is completed when the user has found all the facts and answered all the quiz pop-ups. They are then free to explore further or exit the application.

\subsection{Freedom to Explore, Freedom to Learn}

One of the major aspects of Tenochtitlan is the freedom the user is given within the environment; this makes use of the 'Exploration' game mechanic as described by [18] to encourage users to explore and discover.

A study by [19] also demonstrated that the use of game design principles, such as the score system, lead to greater learning outcomes. This has been integrated to provide feedback to the user, but has been designed in a way that allows the user to learn at their own pace, gives them plenty of time to explore and immerse themselves in the environment. 


\subsection{VR Guidance and UI}

Research into VR-specific development provided important considerations for the application.

To avoid breaking the user's immersion in the environment several precautions were taken. UI elements were kept minimal and unobtrusive (UI reticule, score's basic aesthetic) [20]; and audio cues were used to guide the player toward points of interest without the need of non-diegetic maps/arrows [21].

The large temples in the environment serve as permanent visual reference points in the player's line of sight, an aspect which helps to avoid user disorientation [21]. User visual comfort is further aided by making key elements in the environment provide subtle interactive visual feedback e.g. points of interest being highlighted [20].

\section{Evaluation}

Initial testing of Tenochtitlan has been conducted to gauge its effectiveness in its aim to increase user engagement. The initial sample size of 8 included participants aged 1830 , with varying degrees of technological knowledge i.e. first time VR users, experienced VR users, gamers and non-gamers. This helped to emulate a real-world museum situation in which the application would have to be suitable for a large variety of users.

\subsection{Methodology}

Participants were asked to complete a survey on museums and virtual reality before taking part in the interactive quiz. This survey allowed for an initial analysis of the attitudes and perceptions towards virtual reality use in museums. They were then briefed on the controls and their objectives within the environment before taking part in individual supervised play sessions. During these sessions, observations were made regarding each user's completion time, number of correct answers, perceived ease of controls and how they reacted/responded to the environment. Finally, participants were briefly interviewed after their session to determine how they rated their engagement levels, knowledge of the subject and how they would compare the application with a traditional exhibit.

\subsection{Post-Completion Interview Responses}

An initial overview of the responses provided by the interviews show that $75 \%$ of participants rated their engagement levels in Tenochtitlan as "high" or "very high", with $87.5 \%$ rating their engagement with the subject matter higher than that of traditional text/image exhibit information delivery (Fig. 3), 62.5\% also felt that they had learnt interesting new facts through the VR environment (Fig. 4). When asked whether they found the experience entertaining $87.5 \%$ answered "yes", with $62.5 \%$ going on to state that the application made them want to learn more about the Aztecs. 


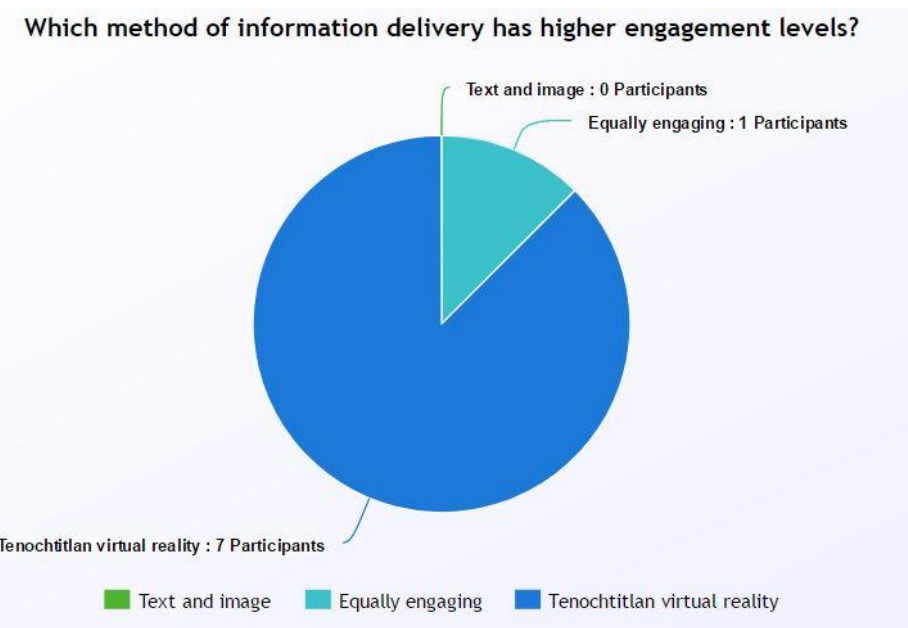

Fig. 3. Tenochtitlan participants' engagement level comparison

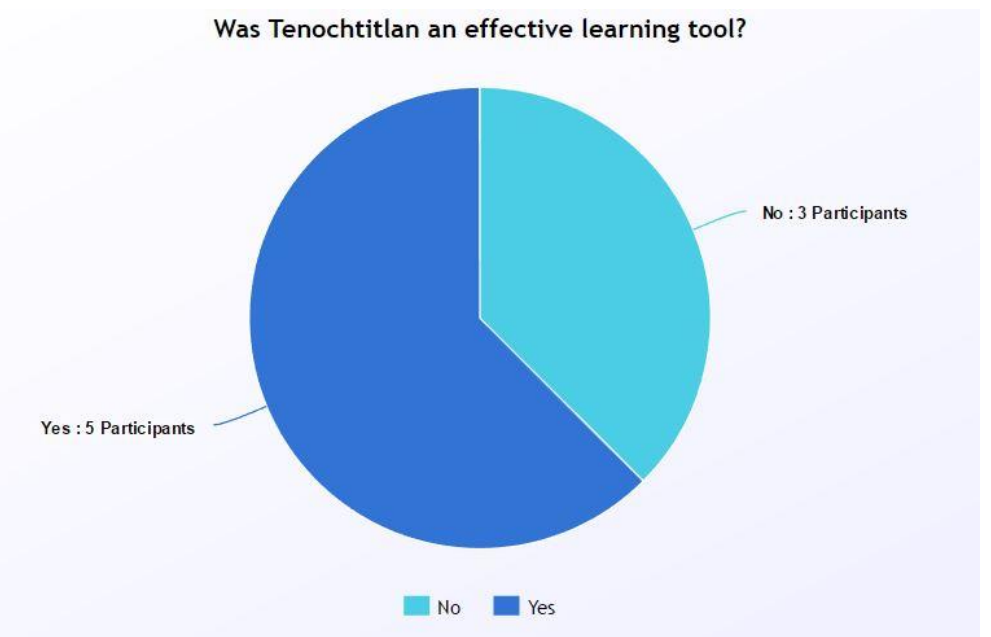

Fig. 4. Participants' opinions on Tenochtitlan's effectiveness as a learning tool

\subsection{Data Analysis}

Tenochtitlan was estimated to take between 12-15 minutes to complete. The longest play time lasted 25 minutes, the shortest was 9 minutes, and the average was 16 minutes (Fig. 5). 


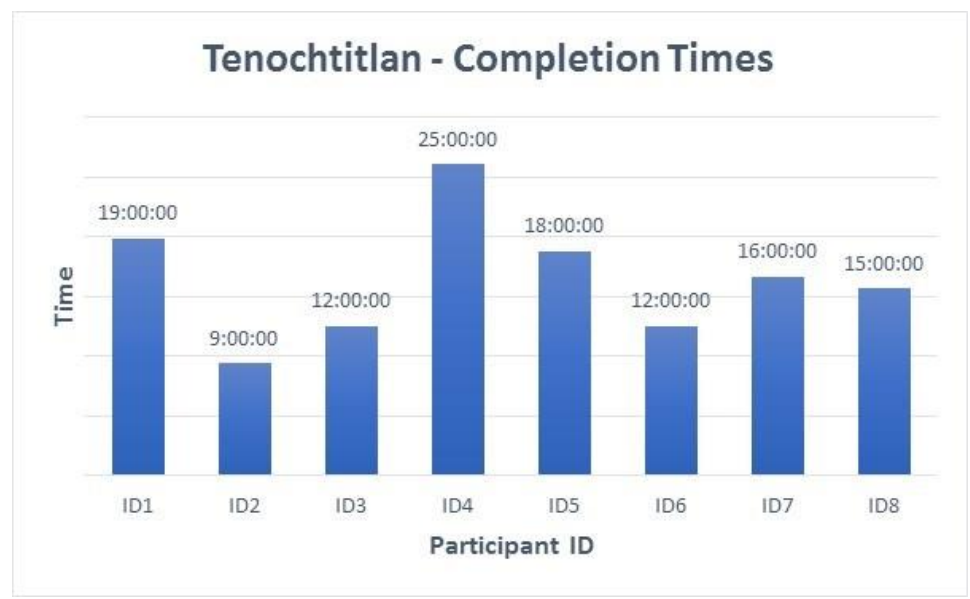

Fig. 5. Tenochtitlan VR quiz - participant completion times.

Users could score a maximum of 1000 points (100 per question). Only one participant managed a perfect score, the lowest was 400, and the average score was 675 (Fig. $6)$.

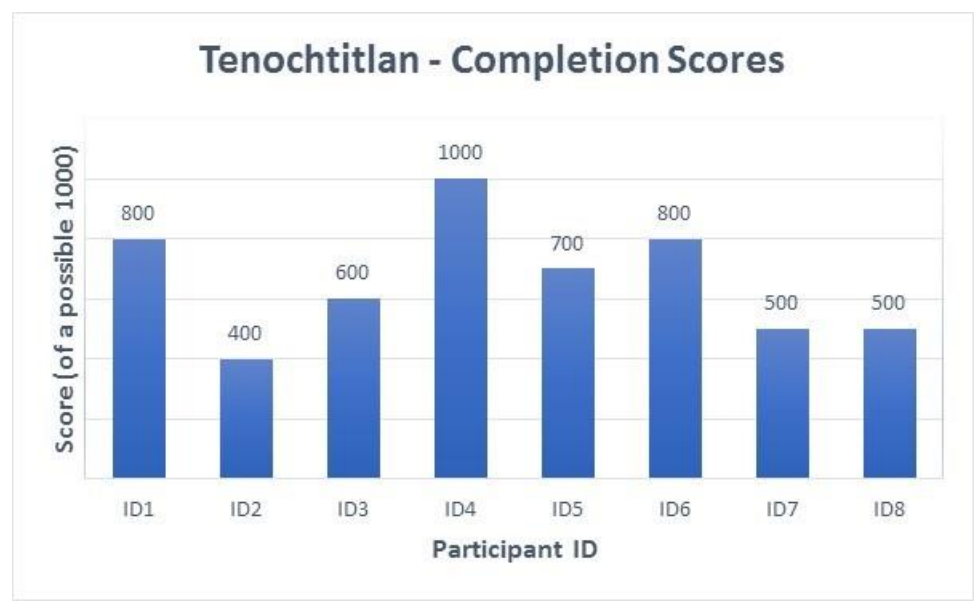

Fig. 6. Tenochtitlan VR quiz - participant completion scores.

Players moved much quicker between the set of ten questions than the set of 10 preceding facts. This may be due to players becoming familiar with movement in virtual reality. 


\section{Conclusion}

In this paper, we have proposed and developed a VR application for young adults, Tenochtitlan, designed to increase user engagement with a museum exhibit, and enhance subject knowledge through interactive learning.

The initial evaluation results have shown that users found Tenochtitlan engaging and entertaining, more so than traditional exhibit information delivery methods, and improved their knowledge on the subject matter through the interactive quiz.

The mechanics within Tenochtitlan has been proved suitable for participants who were familiar with videogame controls and those who were not, an element that would be essential in a real museum setting.

This study was unable to test the application in a real museum environment, so direct comparisons with user engagement with a specific exhibit were unavailable.

Future work in this area would primarily look at creating a new application as a complementary tool for an existing museum exhibit, while studying and comparing the effectiveness of the VR application, in both engagement and education, against the physical museum environment.

\section{References}

1. Department for Culture, Media \& Sport, https://www.gov.uk/government/uploads/system/uploads/attachment_data/file/562676/Focus_on_museums_and_galleries_final.pdf, last accessed 2017/04/02.

2. Poser, S.: Leisure Time and Technology. In: European History Online (EGO), Institute of European History (IEG), Mainz, Germany (2011).

3. Statista Virtual reality interest in the U.S. by age group 2015, https://www.statista.com/statistics/456812/virtual-reality-interest-in-the-united-states-by-age-group/, last accessed 2017/04/09.

4. Mujber, T., Szecsi, T. and Hashmi, M.: Virtual reality applications in manufacturing process simulation. In: Journal of Materials Processing Technology 155-156, pp.1834-1838. Elsevier, Amsterdam, Netherlands (2004).

5. Lepouras, G. and Vassilakis, C.: Virtual museums for all: employing game technology for edutainment. In: Virtual Reality, 8(2), pp.96-106. Springer, London, UK (2004).

6. Rae, J. and Edwards, L.: Virtual reality at the British Museum: What is the value of virtual reality environments for learning by children and young people, schools, and families? In: MW2016: Museums and the Web 2016. Los Angeles, USA (2016).

7. National History Museum Trailer for David Attenborough's Great Barrier Reef Dive, http://www.nhm.ac.uk/discover/david-attenborough-great-barrier-reef-dive-trailer.html, last accessed 2017/04/06.

8. TechRadar VR takes you to London's Natural History Museum from anywhere in the world, http://www.techradar.com/news/wearables/vr-experience-helps-you-learn-from-london-snatural-history-museum-anywhere-in-the-world-1328499, last accessed 2017/04/06.

9. Pujol Tost, L. and Economou, M.: Exploring the suitability of Virtual Reality interactivity for exhibitions through an integrated evaluation: the case of the Ename Museum. In: Museology, 4. Department of Cultural Technology and Communication, Greece (2007). 
10. Bay, H., Fasel, B. and van Gool, L.: Interactive Museum Guide: Fast and Robust Recognition of Museum Objects. In: International Workshop on Mobile Vision, pp.1-4. ACM Press, New York, USA (2006).

11. Zoubola N., Fokides E., Tsolakdis C and Vratsalis C.: Virtual Reality and Museum: An educational application for museum education. In: International Journal of Emerging Technologies in Learning (iJET), vol. 3, pp. 89-95. International Association of Online Engineering (2008).

12. Roussou, M.: Immersive Interactive Virtual Reality in the Museum. In: Proceedings of Trends, Technology, Theming \& Design in Leisure \& Entertainment Conference, (2). Foundation of the Hellenic World, Greece (2002).

13. Döpker, A., Brockmann, T. and Stieglitz, S.: Use Cases for Gamification in Virtual Museums. In: Jahrestagung der Gesellschaft für Informatik, pp. 2308-2321. Gesellschaft für Informatik, Koblenz, Germany (2013).

14. Podgorny, J.: Studying Visitor Engagement in Virtual Reality Based Children's Science Museum Exhibits (Doctoral dissertation, M.A. University of Chicago). (2004).

15. Carrozzino, M. and Bergamasco, M.: Beyond virtual museums: Experiencing immersive virtual reality in real museums. In: Journal of Cultural Heritage, 11(4), pp.452-458. Elsevier, Amsterdam, Netherlands (2010).

16. Brasseur, L.: Engaging with young people to create the museum of the future (Doctoral dissertation, University of Leicester). (2017).

17. Adams, E. and Dormans, J.: Game mechanics: Advanced Game Design. 1st ed. New Riders, California, USA (2012).

18. Perry, D. and DeMaria, R.: David Perry on game design. 1st ed. Course Technology, Boston, USA (2009).

19. Gauthier, A., Corrin, M. and Jenkinson, J.: Exploring the influence of game design on learning and voluntary use in an online vascular anatomy study aid. In: Computers \& Education, 87, pp.24-34. Elsevier, Amsterdam, Netherlands (2015).

20. Sherman, W.R. and Craig, A.B.: Understanding virtual reality: Interface, application, and design. Morgan Kaufmann Publishers, San Francisco, USA (2002).

21. Jerald, J.: The VR book: Human-centered design for virtual reality. Morgan \& Claypool Publishers, California, USA (2015). 